\title{
The key aspects of online support that older family carers of people with dementia want at the end of life: A qualitative study
}

\author{
Nathan Davies* \\ Centre for Ageing Population Studies, Research Department of Primary Care and Population \\ Health, University College London, Rowland Hill Street, London, \\ NW3 2PF, UK \\ n.m.davies@ucl.ac.uk \\ Orcid ID: 0000-0001-7757-5353; Twitter: @ nathandavies50
}

Steve Iliffe

Centre for Ageing Population Studies, Research Department of Primary Care and Population Health, University College London, Rowland Hill Street, London,

NW3 2PF, UK

Orcid ID: 0000-0003-2806-3997

Jenny Hopwood

Centre for Ageing Population Studies, Research Department of Primary Care and Population Health, University College London, Rowland Hill Street, London,

NW3 2PF, UK

Orcid ID: 0000-0002-9703-5829; Twitter: @jennymhopwood

Nina Walker

Centre for Ageing Population Studies, Research Department of Primary Care and Population Health, University College London, Rowland Hill Street, London,

NW3 2PF, UK

Orcid ID: 0000-0002-2862-8890

Jamie Ross

eHealth Unit, Research Department of Primary Care and Population Health, University College London, Rowland Hill Street, London,

NW3 2PF, UK

Orcid ID: 0000-0001-8720-5911; Twitter: @jamueanne_dr

Greta Rait

Priment Clinical Trials Unit, Research Department of Primary Care and Population Health, University College London, Rowland Hill Street, London, NW3 2PF, UK

Orcid ID: 0000-0002-7216-7294; Twitter: @ gretarait1

Kate Walters

Centre for Ageing Population Studies, Research Department of Primary Care and Population Health, University College London, Rowland Hill Street, London,

NW3 2PF, UK

Orcid ID: 0000-0003-2173-2430

*Corresponding author 


\begin{abstract}
Aim: Family carers towards the end of life face a range of difficult challenges and have high levels of support needs. The aim of this study was to explore the challenges older (over 65 years) family carers of people with dementia face towards the end of life and their support needs which could be addressed by online support.
\end{abstract}

Methods: Qualitative study using semi-structured interviews with 23 current and former family carers of people with dementia in England in 2016-2017. Interviews were analysed using thematic analysis.

Results: Most family carers interviewed had positive views of receiving support online via a website. Participants described a series of challenges they felt online support could address and help support them with when caring for someone with dementia towards the end of life: 1) feeling prepared and equipped; 2) feeling connected and supported; 3) balancing their own needs with those of the individual; and 4) maintaining control and being the co-ordinator of care. However many valued a mix of technology and face-to-face interaction in receiving support. Conclusions: This study has identified the key challenges for older family carers at the end of life that could be met by online support. Online support offers a source of support to supplement face-to-face interaction, as many family carers still wish to talk to someone in person.

Keywords: Dementia, End of life, Palliative care, Caregivers, Internet 


\section{Background}

Dementia is a chronic neurodegenerative syndrome and umbrella term used to describe a range of different symptoms, typically characterised by cognitive and functional decline, with a number of underlying causes (Alzheimer's Disease International, 2015). The most common cause of dementia is Alzheimer's disease (World Health Organization (WHO), 2012). There are currently 50 million people living with dementia worldwide and this is expected to rise to 152 million by 2050 (World Health Organization, 2017). Dementia is a terminal condition and is now the leading cause of death in the UK (Office for National Statistics, 2016). Family and friends provide a large proportion of care to people with dementia and act as advocates throughout the dementia trajectory. There are currently estimated to be about 700,000 family carers of people with dementia in the UK (Lewis, Karlsberg Schaffer, Sussex, O'Neill, \& Cockcroft, 2014). The unpaid care family carers provide save the UK and US economies around $£ 11$ billion and \$232 billion respectively a year, by reducing the burden on health and social care services (Alzheimer's Association, 2018; Alzheimer's Society, 2014).

At a time when the overall number of people with dementia is increasing, and the pressure on health and social care systems is rising, there has been a shift of emphasis from formal care services providing care, to family carers providing care at home (Alzheimer's Association, 2014, 2018). However, caring for someone with dementia is a challenging role and over-reliance on family carers can impact on their physical and psychological health (Kneebone and Martin, 2003). The end of life can be a particularly challenging time for family carers physically and emotionally (Peacock, 2012), many people with dementia wish to remain at home with their family even when care at home may not be the best place (Nakanishi and Honda, 2009; 
Wiggins, Droney, Mohammed, Riley, \& Sleeman, 2019) . At this time family carers can find it difficult to leave the home to access support.

There is growing research exploring the experiences of family carers of people with dementia towards the end of life (Broady, Saich, \& Hinton, 2018; Davies, Maio, Rait, \& Iliffe, 2014; Hennings and Froggatt, 2016; Hennings, Froggatt, \& Keady, 2010; Peacock, 2012; Raymond et al., 2014). Studies report a lack of support for family carers (Broady, et al., 2018; Davies, et al., 2014; Hennings and Froggatt, 2016; Hennings, et al., 2010; Peacock, 2012; Raymond et al., 2014), a lack of knowledge among family carers about care needs and what to expect at the end of life with a need for more 'information', usually regarding progression and specific medical treatment or symptoms (Broady, et al., 2018; Davies, et al., 2014; Hennings, et al., 2010; Peacock, 2012). However, rarely do studies report on how these support needs could be met for family carers.

The support and information that family carers need at the end of life could potentially be helped by online support. In this paper online support refers to include webtools, emodules, online forums, websites and apps. The use of websites for information on health and care, such as the NHS website in the UK (www.nhs.uk), which provides information on a range of conditions and treatments, is increasing. Online support can provide informational, emotional and practical support tailored to the individual that is always available, directly in the home, which could assist family carers who are unable to leave the person with dementia (Pal et al., 2018). Family carers in other groups including those caring for ill and wounded soldiers have reported improved access to information and resources using online support (Vaughan et al., 2018), and 
family carers of people with cancer report they like the flexible approach online support can provide (Heynsbergh, Heckel, Botti, \& Livingston, 2018). A systematic review of the literature found a limited number of online support interventions aimed at supporting family carers of people with dementia, and none focussing on end of life (Hopwood et al., 2018). This review found that previous online support used a combination of support options including: contact with care professionals, peer support from other family carers, decision support and psychological support (Hopwood, et al., 2018). Evaluation of the efficacy of these interventions has indicated positive impacts on carer well-being, depression, anxiety and burden (Hopwood, et al., 2018).

Many family carers of people with dementia are spouses and are older themselves (over 65 years) (Brodaty and Donkin, 2009). Statistics demonstrate the proportion of family carers caring for someone with dementia increases with age, with carers over the age of 85 most likely to be caring for someone with dementia (54\%) (NHS Digital, 2017). Despite statistics demonstrating internet use is increasing among those over 65 years (Office for national Statistics, 2017), at present this group are the least skilled to use online support (Choi and DiNitto, 2013; Kim, 2015). It is important to target this group to understand if online support would be beneficial to close the support gap that family carers report (Broady, et al., 2018; Davies, et al., 2014; Hennings and Froggatt, 2016; Hennings, et al., 2010; Peacock, 2012; Raymond, et al., 2014). Furthermore, it is unclear what support and information older family carers would want from online support towards the end of life. 
The aim of this study was to explore the challenges older (over 65 years) family carers of people with dementia face towards the end of life and their support needs which could be addressed by online support.

\section{Methods}

\section{Design}

A qualitative study using semi-structured interviews. Interviews are appropriate when exploring the views and experiences of individuals and are particularly suitable for discussing complex and sensitive topics such as end of life care (Gysels, Shipman, \& Higginson, 2008). Semi-structured interviews allow for key questions and topics to be discussed, whilst ensuring some flexibility to respond to the interviewee (King and Hughes-Jones, 2019).

\section{Participants and recruitment}

Older (over 65 years) family carers (current and former/bereaved) were purposively sampled from three sources in England: 1) Join Dementia Research (JDR) - an online database of people with dementia, family carers and healthy volunteers who have agreed to participate in research;

2) voluntary organisations in England - this included the Alzheimer's Society, Age UK, and local carer organisations in urban, rural and semi-rural areas of south east England; and 3) interested general practices. Research active general practices urban, rural and semi-rural areas of south east England were invited to express an interest in taking part in the study by the Clinical Research Network. Expressions of interests were reviewed by the research team to include general practices with diverse patient lists and a range of locations. 
Family carers were screened over the telephone by the research team to purposively sample a range of internet usage following the categories from the Office for National Statistics (no or minimal use of the internet, moderate use of the internet (e.g. weekly) and high use of the internet (e.g. daily)), relationships to person with dementia and current caring status (i.e. current or bereaved/former carer. Education levels, age, gender, and ethnicity/language were monitored. Recruitment continued until no new ideas and themes were being generated from the data (data saturation) (Glaser \& Strauss, 1967).

Defining when end of life in someone with dementia begins can be challenging for someone with dementia as the trajectory can be uncertain, limiting the ability of professionals to provide an accurate prognosis (Brown, Sampson, Jones, \& Barron, 2013). This has implications for research studies such as this because it is therefore not possible to use a standard definition of end of life, such as the last 12 months of life. For this study participants were informed that this was a study on the end of life and asked to consider whether they were caring for someone at the end of life or had experience of end of life care for a person with dementia. This follows a similar approach to that of a previous study (Davies, Rait, Maio, \& Iliffe, 2017). Older family carers were recruited as there is limited research exploring the views of older family carers (over 65 years) of people with dementia about using the internet to receive support.

\section{Inclusion criteria}

Participants were purposively sampled to include:

- Family carers currently caring for someone with dementia at the end of life or bereaved carers of someone with dementia within last three years (including both those who died either with or from dementia). 
- Family carers 65 years of age and older

\section{Exclusion criteria}

Participants were excluded if:

- Family carers bereaved were within the last 3 months (to ensure it was not burdensome or intrusive at this time)

- Family carers were unable to speak English

\section{Procedure}

Potential participants were invited in writing either by post or email by the NHS service or third sector organisation. Participants were sent an information sheet together with a reply slip and asked to return the reply slip or contact the research team directly if they were interested. Interested participants were contacted by the research team for a more detailed explanation of the study and to check eligibility. Dates and times convenient to the participants were organised with the eligible participants, for a face-to-face interview at their own home or at the University (participants were given the choice). Participants provided written informed consent. Potential participants on the JDR website were contacted by email directly by the research team (in signing up to the website they consent to direct contact by the research team), and asked to reply to the email or telephone the research team if they were interested.

Interviewers were two psychologists (authors initials blinded for peer review) and one general practitioner (authors initials blinded for peer review). The interviewers were experienced qualitative researchers and had experience of working with people with dementia and family carers in previous research studies or clinical practice. Interviews were guided by an interview 
schedule developed in collaboration with an expert steering group and patient and public involvement meetings. These meetings which consisted of family carers (current and former) provided advice on how to word questions sensitively, whilst ensuring important topics were discussed. The groups also helped to identify two popular websites for family carers of people with dementia which could be used to further elicit discussion and ideas within the interviews. The interview schedule which guided the interview was split into three sections: 1) Exploring participants use of the internet generally; 2) exploring what participants found challenging about being a carer for someone with dementia, what support they needed, and how they would like this support delivered, with questions asking for their views on the use of the internet to receive support; and finally 3 ) presenting two existing websites to the participants using a tablet, asking questions about which website they preferred and why. This final phase helped initiate conversations about the positives and negatives of online support and specific features of existing support and what they would want from online support regarding end of life. Interviews took place in 2016 and 2017.

Ethical approval for this study was granted by a National Health Service (NHS) ethics committee (reference number blinded for peer review) and received Health Research Authority approval (HRA). University ethics was provided for recruitment of participants outside of the NHS (reference number blinded for peer review).

\section{Analysis}

All interviews were audio recorded, transcribed verbatim and analysed using thematic analysis (Braun and Clarke, 2006). Analysis was inductive and iterative, using a team approach to 
increase rigour (Barry, Britten, Barber, Bradley, \& Stevenson, 1999; Mays and Pope, 1995), with members of the team from different professional backgrounds to increase discussion and generate further ideas and interpretations of the data. Two researchers (authors initials blinded for peer review) read all the transcripts to familiarise themselves with the data. They independently coded three transcripts and met to discuss a coding framework together with a third researcher (authors initials blinded for peer review) who had read a selection of the transcripts. The agreed coding framework was applied to all transcripts by one researcher (authors initials blinded for peer review) on paper and highlighting. The three researchers met on several occasions to discuss the coding and organise the codes into overarching themes. The meaning and interpretation was agreed with the whole team (all authors).

\section{Findings}

Twenty three participants were interviewed: 19 individual interviews and two were conducted as a pair, five participants were interviewed on a second occasion to provide further information to probe issues as arose from other interviews, continuing the iterative approach to data collection and analysis.

Participants ranged in age from $65-87^{1}($ Mean $=74)$ years old and the majority were female (78\%). A balance of spouses (57\%) and adult children/children in law were recruited, and 52\% were currently caring for someone. The majority of participants identified as white English ethnicity with only two participants not reporting their ethnicity. The majority of participants described their internet use as daily $(\mathrm{n}=17)$, with 3 who described their usage as weekly and 2

${ }_{1}^{1}$ One participant was recruited who was 62 years of age 
never used the internet, finally one described themselves as 'internet savvy'. See table 1 for full demographic details of participants.

\section{Themes}

Participants described a series of challenges they felt online support could address and help support them with when caring for someone with dementia towards the end of life, these were characterised as: 1) feeling prepared and equipped; 2) feeling connected and supported; 3) balancing their own needs with those of the individual; and 4) maintaining control and being the co-ordinator of care.

\section{Feeling prepared and equipped}

Family carers described a lack of information not just at the end of life but throughout the trajectory of dementia, and this all led to a lack of preparation for the end of life. Family carers discussed a desire and need to feel prepared for end of life. There was a need to feel more confident, knowledgeable and prepared about how to manage the medical decline as someone approached the end of life, whilst acknowledging that they don't always know what to ask:

'I think people need to know what to expect at the end of life and I think they need to be educated' (B009, Daughter)

Some thought that instead of the internet helping it can at times make it worse for family carers, making them feel overwhelmed with information: 
'I find sometimes you go into the internet, you put in Alzheimer's or Dementia....And you come up with so much stuff there. You don't know where to start.' (B026, Daughter)

However, some felt with careful design and input from people such as themselves, online support could help to prepare and equip and without causing fear or information overload:

'[...] if it's a carer that is looking for help, they want, they don't want to be distracted. They're already in a little bit of a state. I think it needs to be quite simple and plain and pictures can be distracting, and also make light of the thing.' (C027, Partner)

It was not just about preparing for the future but equipping them to deal with situations in the present moment. Family carers felt that many of the decisions about care and symptoms were reactive, rather than pro-active, often indicating a lack of advance care planning processes. Some felt family carers would use the online support to help equip them with making reactive decisions and choices about care, rather than as a planning tool, preparing for the future:

'People who are coming on to this [website] and are looking for help [now]. And usually it would be, not urgent, but, but current rather than 'what can I expect towards the end of life.' (B025, Son)

Family carers were concerned that there was a lack of openness by professionals and generally in society about the realities and complexities of caring, and online support was seen as an opportunity to share some realities, for example around behaviour changes: 
"Nobody ever talks about behaviour changes" (B004, Husband)

These could be discussed by other family carers in a similar situation as them:

'[...] it might be rather nice to have a carer [family carer] just talking, you know, a little bit, about her experience, how she felt. Something rather simple. [...] sort of "Hello, I'm a carer," you know, [...]' (C022, Wife)

However, they felt that any information about dementia and end of life via online support, should be balanced between openness and not being too distressing:

'But nothing, nothing upsetting. But then you've got to be careful you're not painting too rosy a picture [about end of life] and just seeing lovely old people being looked after' (B019, Daughter)

Online support could also support the need for preparation for beyond the end of life, including after the person has died, .e.g. with preparing funeral arrangements:

'There's issues around what happens after death. [...] I think a lot of carers [family carers], and myself included, because we're all so busy, and tied up with the actual caring, you could neglect the sort of finding out about the end - what you do when the person actually dies.' (C014, Wife) 
Some family carers were already using the internet to try to understand what to expect of end of life:

Interviewer: 'Do you feel when she was reaching end of life that you knew enough about what to expect?'

Participant: 'Only through my own internet searches. If I asked anybody they would say, we don't know.' (B005, Daughter)

However, ultimately family carers did not think there was an existing form of online support such as a website which offered them support at the end of life currently:

Interviewer: 'Is there anything that would draw you to a particular website [such as an end of life website] over other ones?

I don't think there are many out there that would do anything like this. So I think this would be snapped up by a lot of people, an easy-to-use - it's like a one-stop-shop' (B019, Daughter)

Feeling connected and supported

Participants described caring as a lonely experience in which they often felt socially isolated:

'It is very lonely being in the house with somebody that you don't feel competent to deal with' (C014, Wife) 
A web tool was seen as a way to help with this isolation and make people feel connected with others:

'[...] they [family carers] give up everything and then they're just devastated and never pick up their lives again really, some people, you know. So, the more [a website] can put them in to touch with sustainable opportunities for keeping up with carers [family carers] and, you know, sort of whatever, the better.' (C022, Wife)

There was a need to feel connected (i.e. in contact) with others; but views from family carers were often varied as to who they would want to be connected with. For some they wanted it to be professionals; this was often for more medical support and information about end of life care, but for others the need was for connecting with other family carers. It was acknowledged that professionals, particularly at the end of life, did not always have the answers and therefore could not provide support. For day to day and emotional support family carers often preferred to talk to another family carer who could understand their situation:

'I have to tell you that is the most useful thing anywhere that I've ever found, being together with a group of other carers [family carers]. You learn more from them than anyone else.' (C003, Wife)

Online support was seen primarily as an avenue to meet other family carers initially, however after contacting one another they were not looking to just chat online but rather meet face to face. This was highlighted by a former family carer discussing the benefit of an existing website of a 
voluntary system whereby former family carers meet current family carers in local areas to have a chat and provide support:

Interviewer: 'What do you feel about how it's [example of existing website] laid out?

It looks alright to me. I don't know. You see, that's good, isn't it? You go to the shops and meet someone just in this charity thing and then you have a cup of tea and a chat?

Interviewer: Okay, do you like, you might like it [the website] as a way to meet people, would that be right?

Yes, that's right. I mean if they, if, I don't know, some lady somewhere or other has got a husband with dementia, and she can get out, and I could meet her say, in [shop], and have a cup of coffee and a chat.'

(B008, Wife)

However, not all participants were in favour of online support being used to enhance feeling connected and supported. Some advised caution about privacy and the opportunity for some people online to take advantage of what could be seen as a vulnerable group online:

Interviewer: 'one of the ideas that we had, which was a section which you could look up people, other carers [family carers] in your area. 
How do you get around the data? Data Protection Act?

Interviewer: Is that something that you might be worried about?

Not with other carers [family carers], but if somebody finds out that they can, they can contact perhaps vulnerable people. They might - you need to be very careful.' (B019, Daughter)

A secure function such as a private login only page, and interaction from qualified professionals for example was seen as valuable and needed, as you did not always know who you were talking to online:

'I've found in the past, I'm not quite sure who is on chat rooms and things like that, and you never - it's like, it's like walking up to someone in the street and saying, "What would you do if someone's got a sore foot?" you know. So you don't really know who that is.' (B025, Son)

\section{Balancing their own needs with those of the individual}

As the person with dementia and the family carer moved through the different phases of the disease and transitions reaching the end of life, there were several decisions and concerns which were reported to impact upon the family carer's health. Family carers discussed maintaining their own health, both physical and psychological. They described a constant state of adapting and firefighting: 
'I had to adapt our life so much [...] you got over the problems then something else happened' (B006, Wife)

Participants used the key word of ensuring the person with dementia was 'safe' as part of their role, for some this was more difficult to ensure if they were caring remotely or the person still lived alone:

'So she [person with dementia] was very dependent on friends and neighbours, which I felt wasn't fair on them. As I say, in the end, she just wasn't safe there [at home alone].' (B009, Daughter)

However, at times for family carers, in particular for spouses and those who lived with the individual, they described an internal conflict about looking after their own health and wellbeing, putting the person with dementia before their own health:

'I felt desperately sorry for her [mum with dementia], terribly sorry. I never thought about my own health at all, because at the end of the day no matter what I have wrong and I have lived through bowel cancer and I've had a stroke. [...] I've never really bothered to look after myself. I've always put mum first.' (B005, Daughter)

Family carers felt that there was potential for support and coping mechanisms to be provided online as a source of releasing the tensions of caring, for example through discussion forums: 
‘... [Get] different people's views - there's no one right answer. And sometimes it's trial and error. So, if you're getting one person telling you what to do and it doesn't work, what else do you do? But if you've got lots of people telling you, "If that doesn't work, try this. And then if this doesn't work, try that", there's more options.... and also it shows you that there are other people in the same boat and that's a comfort.' (C027, Partner)

However, as the quote above suggests there is also the potential that there are too many opinions online and not all participants felt advice from others was always helpful:

'Well, it would be nice to have their advice, but they're all so different, aren't they? ... if another carer [family carer] told you things, would that be relevant to your mother, father, sister, brother, whoever it is?' (C020, Daughter)

\section{Maintaining control and being the co-ordinator of care}

Family carers felt that in order to receive the care their relative needed they were required to take control and manage the care, acting as a care manager:

'But it's the carer [family carer] and the health service, they're the umbrella that is managing that one person.' (B007, Wife)

'I think it was two or three folders full of names, addresses of organisations, of this and that and the other. It was terrible [managing the persons care], it really was.' (B008, Wife) 
They described battles to negotiate and co-ordinate care, but also to receive financial assistance and aid through benefits and entitlements. Online support has potential for better information sharing to address some of these difficulties, including financial advice and guidance:

'[...] probably initially the 'benefits' would be a great help [...] looking at things like getting attendance allowance and things like that $[\ldots]$ settling an estate, $[\ldots]$ 'Continuing health care' is a minefield. So, the more information you can put on there [online support] the better I think. And it's knowing who to contact. [...] Yes, and I think it would be useful if there's a section that would explain.' (B026, Daughter)

This was particularly problematic for those who were caring remotely from a distance. Family carers described a reliance on services and a difficulty controlling individual situations which progressively became worse as the person became more and more dependent and closer to the end of life, for example co-ordinating different professionals:

'Trying to get services to work with the GP and that.' (B009, Daughter)

Technology was seen as a potential to help with this co-ordination and management of care for remote family carers:

'If there was a computer there [at the persons home], or even through the TV screen, then you could have this dialogue, like Skype, with the patient and the GP with the patient and 
someone from social services, with the patient and the carer [family carer]. So you could have that conversation.' (C015, Son)

\section{Discussion}

This is the first study to our knowledge to explore the preferences specifically of older family carers' of online support when caring for someone with dementia, and specifically focussing on the end of life. Research has demonstrated there is higher internet usage among carers of people with dementia for health care information compared to carers of other groups, although usage decreases with age (Kim, 2015). More recent (2017) statistics however show an increasing number of older people (over 65 years) generally are using the internet (Office for national Statistics, 2017). This study is therefore well timed to uniquely provide evidence of what specific areas the internet could provide support for older family carers of someone with dementia.

Previous research has described family carers' views of a lack of 'information' at the end of life (Broady, et al., 2018; Davies, et al., 2014; Hennings, et al., 2010; Peacock, 2012). However, this study builds on and expands on these findings, suggesting there was a deeper layer to the challenges family carers faced rather than simply a need for more information. They described the need to prepare and equip family carers; a need to feel connected and supported; balancing their own needs with those of the individual with dementia; and finally support with maintaining control and being the co-ordinator of care.

Recent theory informing what works to support family carers of people with dementia states that in supporting family carers the aim is to increase resilience through: 1) extending social assets; 
2) strengthening key psychological resources available to carers; 3) maintaining carer's physical health status; 4) safeguarding carer's quality of life; and 5) ensuring timely availability of key external resources (Parkinson, Carr, Rushmer, \& Abley, 2016). The findings from the current study match closely with these five key areas, and confirm the application of the theory to an end of life care context. However, the current findings suggest that key to supporting family carers is not just resilience and resilience building; but it is also about empowering family carers. The idea of empowerment as core to supporting family carers also aligns with the shift of emphasis from formal care services to more family carers providing care at home (Alzheimer's Association, 2014, 2018). It could be argued that the need for 'information' and co-ordination which family carers discuss when unpacked is a need to be empowered and feel prepared.

Online support could help overcome some of the challenges to empower and prepare family carers, currently posed by limitations of existing health care systems which are stretched to capacity. This would follow similar online support used in other health conditions, for example interventions for family carers of people with cancer which show promise for improving knowledge and communication (Heynsbergh, et al., 2018). Online support such as a website which is evidence based, grounded in the experience of end users, and understands the barriers and facilitators for older adults using the internet (Berkowsky and Czaja, 2018), could improve the access to high quality information and support when family carers are not able to access faceto-face support (Vaughan, et al., 2018).

There are many existing online support interventions for family carers, however none have addressed end of life (Hopwood, et al., 2018). The current study therefore provides vital 
information to what intervention should target when focussing on end of life. An exemplar of an existing intervention is the Dutch 'Dementia Decision Guide', a communication platform for primary care professionals, patients and family. The decision support tool which functions as a 'virtual case manager' is held on a webpage accessible only to individuals nominated by the person with dementia and their family carer (Span et al., 2014; Span et al., 2015). The current findings describing the difficulties of care management may be assisted with such online support of decision making, a key role within care management. Decision making towards the end of life in particular can be difficult and complex for family carers and professionals (Davies, Manthorpe, et al., 2018; Davies et al., 2016; Lamahewa et al., 2018; Pecanac, Wyman, Kind, \& Voils, 2018). Furthermore, the current findings suggest that online support may be particularly helpful for remote family carers who are caring from a distance.

A key aspect for the online support enabling empowerment and care management also involves the interaction with others. What family carers described was not just a need for information and support from knowledgeable individuals, but a desire to have face-to-face interaction. Creating interactive components or the ability to meet offline for face-to-face interaction is important, for some the internet cannot replace face-to-face advice from professionals (Allen, Cain, \& Meyer, 2018). This may be more important for older adults than younger generations who may be more comfortable communicating online (Lifshitz, Nimrod, \& Bachner, 2018). A website may be good for providing general information about a condition such as dementia without the family carer needing to ask or think of a specific question, but when family carers need the answer to a specific question a professional may be better placed (Allen, et al., 2018). The findings from the current study would support this combined model of support. 
Preparing family carers for end of life has previously been identified as a priority (Broady, et al., 2018; Lamahewa, et al., 2018) and this is evident in the attempts to increase advance care planning. The success and effectiveness of advance care planning in dementia however has still not been clearly demonstrated (Hughes, Volicer, \& van der Steen, 2018). Many, including practitioners, people with dementia and families still do not want to engage in significant conversations early enough to enable planning (Davies, et al., 2014). Online support may be a useful tool which equips family carers to discuss future care as and when they are ready, therefore again reinforcing the notion of empowerment. Although end of life requires sensitive discussion which for most is better done face-to-face, online support may allow for initiation of some less sensitive discussions and open the channels for a more in-depth face-to-face discussion. Furthermore the anonymity of online support (e.g. a virtual chatroom) may enable discussion of (and support with) more sensitive topics that may be difficult to raise with others.

Online support, will not suit everyone. Social isolation and feelings of loneliness can be felt more towards the end of life for family carers (Broady, et al., 2018; Davies, Walker, et al., 2018; Murray et al., 2002), and the internet has the potential to heighten these feelings. However, being a family carer at the end of life often requires providing 24 hour care with many family carers unable to leave the house to attend face-to-face support; in these cases the internet may act as a bridge to reduce the isolation that many family carers may feel (Heo, Chun, Lee, Lee, \& Kim, 2015; Hunsaker and Hargittai, 2018). The social connectedness participants discuss in this study is not just for social interaction but also for support. Existing online interventions for family carers of people with dementia have included contact with professionals as part of multi-component interventions (Hattink, Droes, Sikkes, Oostra, \& Lemstra, 2016; Pagan-Ortiz, Cortes, Rudloff, 
Weitzman, \& Levkoff, 2014; Rentz and Von Hoene, 2010; Schaller et al., 2015; Span, et al., 2015), and demonstrated a positive experience for family carers (Rentz and Von Hoene, 2010; Schaller, et al., 2015).

\section{Implications for future research, policy and clinical practice}

The challenges recognised in this paper provide evidence for further development of online support. Despite criticism that the internet and support delivered online support creates a digital divide (Eng et al., 1998; Viswanath and Kreuter, 2007), the results in this paper suggest that some family carers of people with dementia feel that some of the key challenges they face at the end of life can be addressed online. If some needs can be met in this way, then resources can be targeted at those who need face-to-face support, increasing the efficiency of service provision. The study also highlights that traditional delivery of information in the form of text or videos presenting the facts may not be enough. The definition of providing information in the current study appears to include the opportunity for interactive communication, with interaction and support from either family carers or professionals, for some this may include face-to-face interaction potentially using video technology. Those who described minimal use of the internet indicated that with support either themselves or those around them would be able to use this style of online support in their caring role. Of the two who did not use the internet one felt that her family could access support online on her behalf, and the other expressed a desire to engage with the internet and have access to online support. 
The results of this study have been used to inform the development of a prototype online support tool to support family carers of people with dementia towards the end of life, which has been reported separately.

\section{Strengths and limitations}

The study recruited participants from a variety of sources including non-internet based sources such as general practice. Participants mainly consisted of those who used the internet daily, however five participants who did not use it on a daily basis were also recruited, including two who identified as never using the internet. A more diverse range of internet usage among participants may have allowed more detailed exploration of the views on using the internet to support carers.

The large proportion of participants who used the internet daily included in this study may have created a positive bias supporting the use of online support. However, the aim of this paper was to explore what aspects of caregiving or what challenges could be addressed using the internet and not to determine attitudes towards using the internet more generally. There was a spread of education levels and a mix of spouse and adult children carers in the sample, however the study is limited by a lack of ethnic diversity, as the majority were white English.

Due to difficulties of prognostication, there was no set definition of end of life used to recruit participants, such as the final 12 months of life, which may mean that some participants discussed topics which may not be considered 'end-of-life'. 


\section{Conclusion}

A clear message from family carers was that more 'information' was needed about the end of life, and underlying this was a need to be prepared and empowered at the end of life. Dementia is a terminal illness with no known cure and health and social care systems in the UK and across the world are facing large demands and huge financial and resource pressures which means that they are not able to provide the support needed for all family carers. Online support offers a source of support, to supplement face-to-face contact, as many family carers still wish to talk to someone in person. This study has identified the key challenges for family carers at the end of life that could be met by online support.

\section{Funding details}

This work was supported by the National Institute of Health Research School for Primary Care Research (NIHR SPCR) FR11 and Capacity Award 6 programmes [UCL Award 6, 322]. This article presents independent research funded by the National Institute for Health Research (NIHR). The views expressed are those of the author(s) and not necessarily those of the NHS, the NIHR, or the Department of Health

\section{Disclosure statement}

The authors report no conflict of interest.

\section{Data availability statement}

The authors confirm that the data supporting the findings of this study are available within the article. 


\section{REFERENCES}

Allen, F., Cain, R., \& Meyer, C. (2018). Seeking relational information sources in the digital age: A study into information source preferences amongst family and friends of those with dementia. Dementia, p 1471301218786568. doi:10.1177/1471301218786568 Retrieved from https://doi.org/10.1177/1471301218786568

Alzheimer's Association. (2014). 2014 Alzheimer's disease facts and figures. Alzheimers Dementia, 10(2), pp. e47-92.

Alzheimer's Association. (2018). Alzheimer's disease facts and figure. Chicago, IL

Alzheimer's Disease International. (2015). World Alzheimer Report 2015: The Global Impact of Dementia: An analysis of prevalence, incidence, cost and trends. London

Alzheimer's Society. (2014). Dementia UK: Second edition. London

Barry, C. A., Britten, N., Barber, N., Bradley, C., \& Stevenson, F. (1999). Using Reflexivity to Optimize Teamwork in Qualitative Research. Qualitative Health Research, 9(1), pp. 26-44. doi:10.1177/104973299129121677 Retrieved from https://doi.org/10.1177/104973299129121677

Berkowsky, R. W., \& Czaja, S. J. (2018). 2 - Challenges associated with online health information seeking among older adults. In R. Pak \& A. C. McLaughlin (Eds.), Aging, Technology and Health (pp. 3148). San Diego: Academic Press.

Braun, V., \& Clarke, V. (2006). Using thematic analysis in psychology. Qualitative research in psychology, $3(2)$, pp. 77-101.

Broady, T. R., Saich, F., \& Hinton, T. (2018). Caring for a family member or friend with dementia at the end of life: A scoping review and implications for palliative care practice. Palliative Medicine, 32(3), pp. 643-656. doi:10.1177/0269216317748844 Retrieved from http://journals.sagepub.com/doi/abs/10.1177/0269216317748844

Brodaty, H., \& Donkin, M. (2009). Family caregivers of people with dementia. Dialogues in clinical neuroscience, 11(2), pp. 217-228.

Brown, M. A., Sampson, E. L., Jones, L., \& Barron, A. M. (2013). Prognostic indicators of 6-month mortality in elderly people with advanced dementia: A systematic review. Palliative Medicine, 27(5), pp. 389-400. doi:10.1177/0269216312465649 Retrieved from http://pmj.sagepub.com/content/27/5/389.abstract

Choi, N. G., \& DiNitto, D. M. (2013). The digital divide among low-income homebound older adults: Internet use patterns, eHealth literacy, and attitudes toward computer/Internet use. Journal of medical Internet research, 15(5), p e93.

Davies, N., Maio, L., Rait, G., \& Iliffe, S. (2014). Quality end-of-life care for dementia: What have family carers told us so far? A narrative synthesis. Palliative Medicine, 28(7), pp. 919-930.

Davies, N., Manthorpe, J., Sampson, E. L., Lamahewa, K., Wilcock, J., Mathew, R., \& Iliffe, S. (2018). Guiding practitioners through end of life care for people with dementia: The use of heuristics. PLOS ONE, 13(11), p e0206422. doi:10.1371/journal.pone.0206422 Retrieved from https://doi.org/10.1371/journal.pone.0206422

Davies, N., Mathew, R., Wilcock, J., Manthorpe, J., Sampson, E. L., Lamahewa, K., \& Iliffe, S. (2016). A codesign process developing heuristics for practitioners providing end of life care for people with dementia. BMC Palliative Care, 15(68)doi:10.1186/s12904-016-0146-z

Davies, N., Rait, G., Maio, L., \& Iliffe, S. (2017). Family caregivers' conceptualisation of quality end-of-life care for people with dementia: A qualitative study. Palliative Medicine, 31(8), pp. 726-733. doi:10.1177/0269216316673552 Retrieved from http://pmj.sagepub.com/content/early/2016/10/31/0269216316673552.abstract 
Davies, N., Walker, N., Hopwood, J., Iliffe, S., Rait, G., \& Walters, K. (2018). A "separation of worlds": The support and social networks of family carers of people with dementia at the end of life, and the possible role of the internet. Health and Social Care in the Community

Eng, T. R., Maxfield, A., Patrick, K., Deering, M. J., Ratzan, S. C., \& Gustafson, D. H. (1998). Access to health information and support: a public highway or a private road? JAMA, 280(15), pp. 13711375.

Gysels, M., Shipman, C., \& Higginson, I. J. (2008). Is the qualitative research interview an acceptable medium for research with palliative care patients and carers? BMC medical ethics, 9(1), p 7.

Hattink, B., Droes, R. M., Sikkes, S., Oostra, E., \& Lemstra, A. W. (2016). Evaluation of the Digital Alzheimer Center: Testing Usability and Usefulness of an Online Portal for Patients with Dementia and Their Carers. JMIR Research Protocols, 5(3), pp. 193-206. doi:10.2196/resprot.5040 Retrieved from <Go to ISI>://WOS:000381214600019

Hennings, J., \& Froggatt, K. (2016). The experiences of family caregivers of people with advanced dementia living in nursing homes, with a specific focus on spouses: A narrative literature review. Dementia, p 1471301216671418.

Hennings, J., Froggatt, K., \& Keady, J. (2010). Approaching the end of life and dying with dementia in care homes: the accounts of family carers. Reviews in Clinical Gerontology, 20(02), pp. 114-127. Retrieved from href="http://dx.doi.org/10.1017/S0959259810000092

Heo, J., Chun, S., Lee, S., Lee, K. H., \& Kim, J. (2015). Internet use and well-being in older adults. Cyberpsychology, Behavior, and Social Networking, 18(5), pp. 268-272.

Heynsbergh, N., Heckel, L., Botti, M., \& Livingston, P. M. (2018). Feasibility, useability and acceptability of technology-based interventions for informal cancer carers: a systematic review. BMC cancer, 18(1), p 244.

Hopwood, J., Rait, G., Walters, K., Iliffe, S., Ross, J., \& Davies, N. (2018). A systematic review of digital interventions aimed at supporting family carers of people with dementia. Journal of medical Internet research, 20(6)

Hughes, J. C., Volicer, L., \& van der Steen, J. T. (2018). Complexity and gaps: The high-hanging fruit of dementia and palliative care research. Palliative Medicine, 32(3), pp. 591-593. doi:10.1177/0269216318755280 Retrieved from http://journals.sagepub.com/doi/abs/10.1177/0269216318755280

Hunsaker, A., \& Hargittai, E. (2018). A review of Internet use among older adults. New Media \& Society, 20(10), pp. 3937-3954. doi:10.1177/1461444818787348 Retrieved from https://doi.org/10.1177/1461444818787348

Kim, H. (2015). Understanding Internet use among dementia caregivers: results of secondary data analysis using the US caregiver survey data. Interactive journal of medical research, 4(1), p e1.

King, N., \& Hughes-Jones, S. (2019). The interview in qualitative research. In C. Sullivan \& M. A. Forrester (Eds.), Doing Qualitative Research in Psychology: A practical guide (2nd ed.). London: Sage.

Kneebone, I. I., \& Martin, P. R. (2003). Coping and caregivers of people with dementia. British journal of health psychology, 8(1), pp. 1-17.

Lamahewa, K., Mathew, R., Iliffe, S., Wilcock, J., Manthorpe, J., Sampson, E. L., \& Davies, N. (2018). A qualitative study exploring the difficulties influencing decision making at the end of life for people with dementia. Health Expectations, 21(1), pp. 118-127. doi:doi:10.1111/hex.12593 Retrieved from https://onlinelibrary.wiley.com/doi/abs/10.1111/hex.12593

Lewis, F., Karlsberg Schaffer, S., Sussex, J., O'Neill, P., \& Cockcroft, L. (2014). The Trajectory of Dementia in the UK - Making a Difference. London

Lifshitz, R., Nimrod, G., \& Bachner, Y. G. (2018). Internet use and well-being in later life: a functional approach. Aging \& mental health, 22(1), pp. 85-91. 
Mays, N., \& Pope, C. (1995). Rigour and qualitative research. BMJ: British Medical Journal, 311(6997), p 109.

Murray, S. A., Boyd, K., Kendall, M., Worth, A., Benton, T. F., \& Clausen, H. (2002). Dying of lung cancer or cardiac failure: prospective qualitative interview study of patients and their carers in the community. BMJ, 325(7370), p 929.

Nakanishi, M., \& Honda, T. (2009). Processes of decision making and end-of-life care for patients with dementia in group homes in Japan. Archives of gerontology and geriatrics, 48(3), pp. 296-299.

NHS Digital. (2017). Personal Social Services Survey of Adult Carers in England, 2016-17. England: https://digital.nhs.uk/data-and-information/publications/statistical/personal-social-servicessurvey-of-adult-carers/personal-social-services-survey-of-adult-carers-in-england-2016-17

Office for National Statistics. (2016). Deaths registered in England and Wales (Series DR): 2015. London

Office for national Statistics. (2017). Statistical bulletin: Internet users in the UK: 2017. London: https://www.ons.gov.uk/businessindustryandtrade/itandinternetindustry/bulletins/internetuser s/2017\#recent-internet-use-for-those-aged-65-and-over-is-catching-up-with-younger-agegroups

Pagan-Ortiz, M. E., Cortes, D. E., Rudloff, N., Weitzman, P., \& Levkoff, S. (2014). Use of an online community to provide support to caregivers of people with dementia. Journal of Gerontological Social Work, 57(6-7), pp. 694-709. Retrieved from

http://ovidsp.ovid.com/ovidweb.cgi?T=JS\&CSC=Y\&NEWS=N\&PAGE=fulltext\&D=emexa\&AN=615 286457

Pal, K., Dack, C., Ross, J., Michie, S., May, C., Stevenson, F., . . Murray, E. (2018). Digital Health Interventions for Adults With Type 2 Diabetes: Qualitative Study of Patient Perspectives on Diabetes Self-Management Education and Support. J Med Internet Res, 20(2), p e40. doi:10.2196/jmir.8439 Retrieved from http://www.jmir.org/2018/2/e40/

https://doi.org/10.2196/jmir.8439

http://www.ncbi.nlm.nih.gov/pubmed/29463488

Parkinson, M., Carr, S., Rushmer, R., \& Abley, C. (2016). Investigating what works to support family carers of people with dementia: a rapid realist review. Journal of Public Health, 39(4), pp. e290e301.

Peacock, S. C. (2012). The experience of providing end-of-life care to a relative with advanced dementia: An integrative literature review. Palliative \& Supportive Care, 11(2), pp. 155-168.

Pecanac, K. E., Wyman, M., Kind, A. J. H., \& Voils, C. I. (2018). Treatment decision making involving patients with dementia in acute care: A scoping review. Patient Education and Counseling, 101(11), pp. 1884-1891. doi:https://doi.org/10.1016/j.pec.2018.06.017 Retrieved from http://www.sciencedirect.com/science/article/pii/S073839911830315X

Raymond, Warner, A., Davies, N., Manthorpe, J., Ahmedzhai, S., \& lliffe, S. (2014). Palliative care services for people with dementia : A synthesis of the literature reporting the views and experiences of professionals and family carers. Dementia: The international journal of social studies, 13, pp. 96110. doi:10.1177/1471301212450538 Retrieved from doi: $10.1177 / 1471301212450538$

Raymond, M., Warner, A., Davies, N., Iliffe, S., Manthorpe, J., \& Ahmedzhai, S. (2014). Palliative care services for people with dementia: A synthesis of the literature reporting the views and experiences of professionals and family carers. Dementia, 13(1), pp. 96-110. doi:10.1177/1471301212450538 Retrieved from http://dem.sagepub.com/content/13/1/96.abstract

Rentz, M., \& Von Hoene, A. (2010). Best practices. Online coaching for caregivers: using technology to provide support and information. Alzheimer's Care Today, 11(3), pp. 206-209 204p. Retrieved from 
http://search.ebscohost.com/login.aspx?direct=true\&AuthType=ip,shib\&db=jlh\&AN=10507153 7\&site=ehost-live\&scope=site

Schaller, S., Marinova-Schmidt, V., Gobin, J., Criegee-Rieck, M., Griebel, L., Engel, S., . . KolominskyRabas, P. L. (2015). Tailored e-Health services for the dementia care setting: a pilot study of 'eHealthMonitor'. BMC Medical Informatics \& Decision Making, 15(1), pp. 58-58 51p. doi:10.1186/s12911-015-0182-2 Retrieved from http://search.ebscohost.com/login.aspx?direct=true\&AuthType=ip,shib\&db=jlh\&AN=10960791 7\&site=ehost-live\&scope=site

Span, M., Smits, C., Groen-van de Ven, L., Cremers, A., Jukema, J., Vernooij-Dassen, M., \& Hettinga, M. (2014). Towards an interactive web tool that supports shared decision making in dementia: identifying user requirements. Int. J. Adv. Life Sci, 6, pp. 338-349.

Span, M., Smits, C., Jukema, J., de Ven, L. G., Janssen, R., Vernooij-Dassen, M., ... Hettinga, M. (2015). An interactive web tool for facilitating shared decision-making in dementia-care networks: A field study. Frontiers in Aging Neuroscience, 7 (JUN) (no pagination)(128)Retrieved from http://ovidsp.ovid.com/ovidweb.cgi?T=JS\&CSC=Y\&NEWS=N\&PAGE=fulltext\&D=emexb\&AN=605 096571

Vaughan, C., Trail, T. E., Mahmud, A., Dellva, S., Tanielian, T., \& Friedman, E. (2018). Informal Caregivers' Experiences and Perceptions of a Web-Based Peer Support Network: Mixed-Methods Study. J Med Internet Res, 20(8), p e257. doi:10.2196/jmir.9895 Retrieved from http://www.jmir.org/2018/8/e257/

https://doi.org/10.2196/jmir.9895

Viswanath, K., \& Kreuter, M. W. (2007). Health disparities, communication inequalities, and eHealth. American Journal of Preventive Medicine, 32(5), pp. S131-S133.

Wiggins, N., Droney, J., Mohammed, K., Riley, J., \& Sleeman, K. E. (2019). Understanding the factors associated with patients with dementia achieving their preferred place of death: a retrospective cohort study. Age and Ageing

World Health Organization. (2017). Dementia fact sheet

World Health Organization (WHO). (2012). Dementia: a public health priority. Geneva 
Table 1. Demographics of participants

\begin{tabular}{|c|c|c|}
\hline Characteristic & Category & $\mathbf{N}$ \\
\hline \multirow[t]{2}{*}{ Gender (Male) } & Male & 5 \\
\hline & Female & 18 \\
\hline \multirow{2}{*}{$\begin{array}{l}\text { Relationship to } \\
\text { person with } \\
\text { dementia }\end{array}$} & Spouse & 13 \\
\hline & Adult Child & 10 \\
\hline \multirow{4}{*}{$\begin{array}{l}\text { Age at end of formal } \\
\text { education }\end{array}$} & Before 15 years & 2 \\
\hline & $\begin{array}{l}\text { At the age of } 15 \text { or } 16 \\
\text { years }\end{array}$ & 1 \\
\hline & $\begin{array}{l}\text { Between the age of } \\
17-20 \text { years }\end{array}$ & 6 \\
\hline & After 20 years & 13 \\
\hline \multirow[t]{3}{*}{ Internet usage } & Daily & 17 \\
\hline & Weekly & 3 \\
\hline & Never & 2 \\
\hline \multirow{2}{*}{$\begin{array}{l}\text { Current or bereaved } \\
\text { family carer }\end{array}$} & Current & 12 \\
\hline & Bereaved & 11 \\
\hline
\end{tabular}

Missing data on education and use of the internet from one participant 